\title{
A Fundação da Psicanálise e a Epistemologia da Deformação
}

\author{
Tiago Iwasawa Neves \\ Universidade Federal de São João Del-Rei
}

\begin{abstract}
RESUMO
Neste artigo, abordamos a epistemologia histórica de Gaston Bachelard para demonstrar que a psicanálise mantém uma relação de compatibilidade lógica com a ciência. Esta epistemologia afirma que a atividade científica moderna traz como efeito fundamental uma disjunção entre os campos de problema. A psicanálise e a atividade científica moderna são compatíveis porque ambas adotam o mesmo princípio para tratar de um problema: a deformação dos conceitos com os quais lidam. Segundo Bachelard, somente em função de um trabalho de deformação é que as primeiras noções e hipóteses tornam-se conceitos. E apenas conceitos produzidos segundo este trabalho é que serão considerados compatíveis com a lógica proposta pela atividade científica moderna. Portanto, é a partir do conceito de deformação que abordaremos o período inicial da obra de Freud - anos de fundação da psicanálise - procurando demonstrar como o conceito de inconsciente só surge em função de um trabalho de deformação.
\end{abstract}

Palavras-chave: psicanálise; epistemologia da deformação; Freud; Bachelard.

\begin{abstract}
The Foundation of Psychoanalysis and the Deformation's Epistemology

In this article we approach Gaston Bachelard's historical epistemology to demonstrate that psychoanalysis maintains a relation of logical compatibility with science. This epistemology affirms that the modern scientific activity brings the fundamental effect of the disjunction between different fields. Psychoanalysis and modern scientific activity are compatible because they are based on the same principle: the deformation of the concepts they deal with. According to Bachelard, a deformation work is necessary for the initial notions and hypotheses to become concepts. Only concepts produced in accordance with this work can be considered compatible with the logic proposed by modern scientific activity. As such, we take as a starting point the concept of deformation to approach the initial period of Freud's work - the foundation years of the psychoanalysis - aiming to demonstrate that the concept of the unconscious required deformation work to emerge.
\end{abstract}

Keywords: psychoanalysis; deformation's epistemology; Freud; Bachelard.

Este artigo trata da seguinte questão: seria a psicanálise uma ciência? Sabemos que o problema da cientificidade da psicanálise foi fundamental para Freud. O Projeto Para uma Psicologia Científica (1895/ 1996) ilustrou perfeitamente o desejo de Freud em submeter suas descobertas às leis de um discurso científico. No entanto, em primeiro lugar, devemos nos perguntar de que problemas Freud estava tratando quando levantou a questão de um estatuto científico para a psicanálise, uma vez que esse desejo de que a psicanálise viesse a ser reconhecida como a ciência do psiquismo não se realizou. Chama-nos atenção o fato do próprio Freud ter admitido em um de seus últimos textos que a tarefa de tratar objetivamente das neuro- ses ficaria reservada para o futuro (Freud, 1938/1996, p. 210).

Podemos, a partir dessa afirmação, concluir que a psicanálise ao especializar-se como uma clínica pensada fundamentalmente em função da hipótese do inconsciente, não pode admitir como orientação para o tratamento um processo de objetivação científico. Isto porque, por definição, a psicanálise visa estabelecer um tratamento para um sujeito. Freud nos aponta este problema ao dizer que uma de suas preocupações, ao situar esta discordância entre psicanálise e método objetivo de tratamento, foi chamar atenção para a associação-livre como uma técnica de tratamento que não poderia ser negligenciada, pelo fato dela mesma, 
conceitualmente, marcar a realização psicanalítica do conceito de inconsciente. E esta marca não traz nenhum traço que possibilite uma subordinação da psicanálise a qualquer tipo de procedimento objetivante. É válido lembrar que um procedimento objetivante não é a mesma coisa que um processo de objetivação. Só o segundo pode ser considerado síncrono ao espírito científico. A característica primordial do procedimento objetivante é sempre tomar um problema não-objetivo - a saber, o sujeito - como objeto. Devemos criticar esta posição: ao tomar o sujeito como um objeto, estes procedimentos querem se afirmar como científicos. O princípio cientificista, como veremos adiante, é a base de sustentação deste tipo de pensamento.

Este problema especifica-se ainda mais ao constatarmos que o termo psicanálise foi proposto por Freud em 1896 com o intuito de fundar um novo modo de tratamento para a histeria: a associação-livre que, ao surgir como técnica e regra fundamental do tratamento, não pressupõe outra coisa senão pensamentos a serem clinicados. "O que são estes sonhos, senão sonhos relatados? É no processo de sua narrativa que se lê o que Freud chama o sentido do sonho" (Lacan, 1975, p. 9). A psicanálise ao se fundar como clínica traz como consequência a impossibilidade de considerarmos o seu campo de problemas como científico. Esta impossibilidade pode ser lida em Freud a partir do momento em que o conceito de inconsciente se torna fundamental para a psicanálise. Fundamental no sentido de que só em referência a este é possível uma prática psicanalítica. E não devemos confundir esta prática com a prática científica.

Podemos assim pensar em uma tensão constante no pensamento freudiano quando nos questionamos sobre o estatuto científico da psicanálise. Propomos, portanto, neste artigo, uma distinção das pretensões de Freud e aquilo que ele produziu conceitualmente. Tal tensão pode ser remetida aos próprios anos de fundação da psicanálise. Será sob os votos de estar criando uma nova ciência que Freud lança mão do termo psicanálise em 1896? Ou seria, antes, por estar dando atenção a um novo problema que Freud julga necessário um novo termo? Ora, acreditamos que o termo psicanálise não é apenas uma mudança de nomenclatura. Pretendemos, fundamentalmente, criticar esta posição. Acreditamos que não se trata da fundação de um nome, mas antes, de um problema. A psicanálise se torna possível como prática somente por Freud ter se dado novos problemas; novas questões, que por consequência, romperam com o ideal cientificista de suas teorizações.

Se uma subordinação dos problemas psicanalíticos a leis científicas é uma pretensão no Projeto, a Interpretação dos Sonhos (1900/1996) - a qual demarca de forma sistemática o conceito fundante da psicanálise, o inconsciente - deve ser encarada como o que decreta o abandono dessa pretensão pela psicanálise. $\mathrm{O}$ que pretendemos demonstrar é que é justamente o conceito de inconsciente que nos possibilita pensar, no âmbito de uma compatibilidade lógica, a relação da psicanálise com a ciência. No Projeto, subordinação; na Interpretação dos Sonhos, compatibilidade. Nossa hipótese aponta para uma ruptura entre os problemas científicos e clínicos. E por se tratar de uma ruptura é que a psicanálise não pretende, a partir do conceito de inconsciente, se subordinar à ciência, mas sim ser compatível com a lógica de pensamento desta. Esta lógica de pensamento diz respeito à maneira pela qual a psicanálise e a ciência encaminham suas questões. Se há um laço que une a psicanálise e a epistemologia bachelardiana, este deve ser buscado não em um mesmo problema a ser tratado, mas em um mesmo princípio adotado. Nós chamaremos este princípio, em homenagem a Gaston Bachelard, de epistemologia da deformação.

É esta lógica de pensamento que, em seguida, pretendemos destacar como um dos efeitos do surgimento do pensamento científico moderno. Este será o primeiro momento de nosso artigo. Em um segundo momento, apontaremos que é em função do que definiremos como a epistemologia da deformação que podemos situar a compatibilidade lógica entre a psicanálise e ciência. Na conclusão, partiremos do aforismo lacaniano de que a psicanálise só pode surgir em um mundo onde há ciência para pensarmos as consequências desta compatibilidade na constituição do campo de problemas da psicanálise.

\section{Epistemologia da deformação}

Percebemos uma modificação epistemológica profunda ao analisarmos os efeitos do surgimento da atividade científica moderna. Gaston Bachelard, ao longo de sua obra dedicada principalmente à epistemologia da física e da química, situou essa modificação em torno de algumas coordenadas que foram subvertidas em função de uma nova lógica de pensamento. De fato, o advento da atividade científica moderna não implica mais na busca de um mundo natural, no qual os objetos estariam dispostos hierarquicamente formando o conjunto do universo. A principal tese de 
Koyré (1991) é que a ciência traz com ela a implicação do moderno. Entendemos o advento de um mundo moderno como uma ruptura em relação ao mundo antigo; função de um corte epistemológico, o qual é possível de ser pensado a partir do momento em que a física se torna matematizada. Esse é o papel da epistemologia histórica de Bachelard: defender a tese de que um dos efeitos da matematização da física é o estabelecimento de novas coordenadas para definirmos qual o sentido do problema que está em jogo para uma atividade estritamente objetiva. Estas novas coordenadas são: um mundo infinito, sem qualidades e sem hierarquias. Enfim, características de um mundo moderno, que definiremos então, como um mundo afetado pela atividade científica. Para tratarmos destas novas coordenadas, privilegiaremos a subversão empreendida pela epistemologia de Bachelard na definição de dois termos: objeto e experiência científica.

É importante assinalarmos que o termo epistemologia histórica foi proposto por Dominique Lecourt em um livro publicado em homenagem ao pensamento de Bachelard - L'Épistémologie Historique de Gaston Bachelard (1969). Nesse artigo, estendemos esta denominação a todos os autores em epistemologia - entre eles Alexandre Koyré, Robert Blanché - que situam o corte epistemológico como o operador lógico de uma novidade.

Afirmar que a física matematizada é o que expressa a realização da ciência moderna, equivale a dizer que esta física é uma teoria conexa a uma experiência. Esta conexão e o termo que a expressa - objetivação são novos e próprios à epistemologia histórica, por isso, em primeiro lugar, é um erro equipará-los a um empirismo do tipo preconizado por Bacon. Segundo Koyré (1991), o papel de Bacon e de Galileu (cientista que na visão de Koyré instaura a física matematizada) na história das ciências não é da mesma ordem. Isso porque a observação e experiência através dos sentidos - implicações do empirismo de Bacon - servem mais como obstáculo epistemológico no caminho de uma objetivação, e menos como um método da ciência moderna. De fato, não devemos confundir experiência com experimentação. É contra a noção de empirismo desenfreado, isto é, sem uma ordem de produção para uma experimentação, que se coloca o pensamento científico moderno. Mas, esta posição não implica que a ciência não esteja preocupada com a observação e experimentação. E implica menos ainda que a teoria nos dizeres de Koyré, universo do artifício - não traga a marca de um real.
Ao contrário do empirismo e de um primado da experiência vulgar, devemos considerar teoria e práxis a partir de uma nova ligação, própria ao mundo científico. Bachelard (1978) demonstrou que na ciência moderna o momento da experimentação, assim como seu instrumento, são considerados teorizações precisas. Um exemplo clássico desta demonstração é o telescópio. Este instrumento não se reduz a uma mera ampliação sensorial capaz de fornecer de forma mais precisa os dados da experiência sensível. Devemos pensá-lo como uma teoria realizada. A instrumentalização da experiência não nos informa, em hipótese alguma, uma experiência sensível imediata. O real matematizado da física moderna não é da ordem de uma realidade desvelada, mas sim de uma produção. Desse modo, Galileu não voltou seu telescópio para os astros para "vê-los" melhor, mas sim para interrogá-los. "A experimentação consiste em interrogar metodicamente a natureza" (Koyré, 1991, p. 154). Portanto, o telescópio é uma teoria realizada, ou dito de outra maneira, "um instrumento, na ciência moderna, é um teorema coisificado" (Bachelard, 1977, p. 129). Neste contexto de debate entre experiência e experimentação, o conceito de definição operatória de Jean Ullmo (1967) é esclarecedor: "Uma definição operatória é uma definição que comporta a descrição de um processo regular para referir, medir, mais geralmente atingir e identificar o conceito definido. A primeira exigência metodológica da ciência é a de utilizar apenas conceitos assim definidos" (Ullmo, 1967, p. 27).

Assim, se o telescópio não é fabricado no intuito de "descobrir" os astros, é porque há uma teoria anterior a este instrumento que define operatoriamente, por exemplo, as órbitas elípticas dos planetas em torno do sol. É por esta razão que a instrumentalização e a experimentação designam experiências passíveis de serem repetidas. $\mathrm{O}$ caráter de repetição é fundamental para a atividade científica moderna porque a partir deste, podemos desqualificar a pretensão de que a ciência se ocupa de uma experiência, e de que esta última é a sua condição. Ullmo (1967) acredita que é a partir de então que se estabelece um fosso entre a experiência propriamente científica e qualquer outro tipo de experiência. É por esta razão que Lacan afirma (1964/1998) que não basta uma prática evocar a experiência para se dizer científica. A experiência mística, por exemplo, não é científica, visto que não é repetível.

E quanto a noção de objeto? Será que os objetos científicos são "coisas", ou antes, conceitos definidos operatoriamente? Percebemos que a ciência moderna estabelece também outro sentido para conceito de 
objeto. Bachelard afirmou na Psicanálise do Fogo (1999) que não basta falar em objetos para se crer objetivo. Em primeiro lugar, porque a ciência não encontra os seus objetos prontos na natureza; ela os produz a partir da definição operatória. É aqui que podemos inserir o conceito de objetividade na epistemologia bachelardiana:

De fato, a objetividade científica só é possível se inicialmente rompemos com objeto imediato, se recusamos a sedução da primeira escolha, se detemos e refutamos os pensamentos que nascem da primeira observação. Toda objetividade, devidamente verificada, desmente o primeiro contato com o objeto. Ela deve, em primeiro lugar, criticar tudo: a sensação, o senso comum, inclusive a prática mais constante, e finalmente a etimologia, pois o verbo, feito para cantar e seduzir, raramente coincide com o pensamento. Longe de maravilhar-se, o pensamento objetivo deve ironizar. Sem essa vigilância malévola, não assumiremos jamais uma verdadeira atitude objetiva (Bachelard, 1999, pp. 1-2).

A subversão das noções de experiência e objeto operadas pela ciência moderna trouxe como consequência direta a possibilidade desta última recusar qualquer realidade que não seja produzida. Não há mais uma realidade independente de um pensamento que a torna possível; não existe nenhum objeto que não seja definido operatoriamente. Dessa forma podemos deslocar o obstáculo epistemológico, antes situado nas noções de objeto e experiência, para a própria ideia de um obstáculo realista. Seja evocando a experiência ou os objetos, sempre encontramos, segundo Bachelard (1996), implicada nestas filosofias a ideia de uma realidade que se impõe ao pensamento: "O realismo é uma metafísica infecunda, já que susta a investigação, em vez de provocá-la" (Bachelard, 1996, p. 27). E por que infecunda? Ora, se pensarmos a atividade científica como sendo da ordem de produção de novos problemas e questionamentos, não faz sentido falarmos em função realista que pretende sempre colocar um indubitável para o conhecimento, isto é, uma instância da qual não partem questionamentos, mas, antes, apenas reconhecimentos. Não devemos nos esquecer que ao evocarmos a ideia de um indubitável nos deparamos imediatamente com a ideia de imutável e eterno.

Entretanto, ao contrário dessa posição realista, a ciência é bem-sucedida justamente pelo seu caráter de infinitude e parcialidade. E mais, ela triunfa exatamente por admitir como um de seus princípios uma epistemologia da deformação contra a face realista dos sistemas anteriores de conhecimento. Como diria Robert Blanché:

Ora, é esta tese da imutabilidade e da necessidade absoluta dos princípios diretores do conhecimento que a ciência atual obriga a pôr em questão. (...) A lógica formal, a matemática especulativa, a física teórica, quer dizer, as ciências que são, por excelência, fruto da razão, foram, por caminhos diversos, levadas a contestar a validade absoluta dos princípios que se tinha até então julgados constitutivos da razão (Blanché, 1983, pp. 20-22).

A epistemologia da deformação é fecunda ao nos depararmos com o problema em torno dos conceitos científicos. Segundo Bachelard, um conceito científico só pode ser produzido, nunca dado de antemão. Se há uma recusa radical de uma realidade independente de uma operação de pensamento, o trabalho científico se dá sempre no sentido de um recomeço. Portanto, para o espírito científico uma rede conceitual serve para estruturar uma experiência. Uma primeira consequência que temos, a partir de então, é que não faz sentido falar em conceitos isoladamente, pois estes só são definidos a partir da relação em que se encontram tramados. E mais, a formação de um conceito científico se coloca sempre no sentido de um trabalho. Não basta evocarmos uma palavra para designar um conceito. Ao contrário dessa posição que procura definir a priori os conceitos com os quais lida, Bachelard demonstrou que este trabalho conceitual, próprio ao espírito científico, se realiza por uma "complicação" de um sentido já estabelecido. Dito de outra maneira, a realização de um conceito não acontece em função deste se colocar em conformidade com a realidade, mas sim de que ele possa funcionar como condição para se pensar uma realidade. Bachelard definiu esse trabalho da seguinte forma:

A conceitualização totaliza e atualiza a história do conceito. Além da história, impelida pela história, ela suscita experiências para deformar um estágio histórico do conceito. Na experiência, ela procura ocasiões para complicar o conceito, para aplicá-lo, apesar da resistência desse conceito, para realizar as condições de aplicação que a realidade não reunia. É então que se percebe que a ciência constrói seus objetos, que nunca ela os encontra prontos. A fenomenotécnica prolonga a fenomenologia (Bachelard, 1996, pp. 76-77).

Em função dessa definição podemos extrair duas consequências. Em primeiro lugar, vemos que não há possibilidade de estabelecermos um método regularmente fecundo para a ciência. Esta encontra sua 
fecundidade ao trabalhar sempre na perspectiva de que o método possa fracassar. A condenação de um método sempre nos apontará uma novidade. É por esta razão que Bachelard afirmou que uma crise nos métodos "é imediatamente uma consciência da reorganização do método" (Bachelard, 1977, p. 125). Em função disso, um método nunca é anterior ao sentido do problema. A ciência triunfa exatamente por seguir um caminho oposto ao de uma unidade metodológica e da colocação de um método anterior ao sentido do problema.

Em segundo lugar, na perspectiva de Bachelard, trabalhar um conceito não é outra coisa senão deformá-lo. Dominique Lecourt (1969) afirmou que a epistemologia bachelardiana admite um sentido totalmente novo para a noção de erro. O caráter fecundo da ciência está intimamente relacionado à tese de que o erro não é outra coisa senão uma oportunidade de deformação, uma possibilidade de uma nova organização dos conceitos. "A positividade do erro faz parte dos axiomas de sua epistemologia" (Lecourt, 1969, p. 41). Assim, acreditamos que é a partir da epistemologia da deformação que podemos sustentar nossa tese de que a psicanálise e a ciência são compatíveis por adotar princípios semelhantes para encaminhar os problemas. É esse modo de se encaminhar as questões - que ressalta, além da separação dos campos de problemas, um impasse como condição para a produção de uma experiência nova e a possibilidade de formulação de novos conceitos a partir destes impasses que podemos definir a característica fundamental do espírito científico.

\section{Deformação e os anos de fundação da psicanálise}

No Projeto Para uma Psicologia Científica (1895/1996) podemos demarcar um posicionamento de Freud frente às ciências de sua época: vemos seu interesse em estabelecer uma explicação para os processos psíquicos, tomando por base os processos neuronais a partir de uma fisiologia do sistema nervoso. Podemos indicar, de saída, que o interesse de Freud em fazer da psicanálise uma ciência se coaduna ao objetivo que traça ao escrever o seu Projeto. Escreve ele que o objetivo de tal texto "é estruturar uma psicologia que seja uma ciência natural: isto é, representar os processos psíquicos como estados quantitativamente determinados de partículas materiais especificáveis" (Freud, 1895/1996, p. 395). Essas "partículas materiais", a saber, são os neurônios. Dessa forma, é a partir de um funcionamento neuronal que Freud pretende representar os processos psíquicos.
No entanto, a despeito desta exigência científica que é esboçada no Projeto, Jacques Lacan nos disse, em seu seminário A Ética da Psicanálise (195960/1988), que esta exigência não possui relação com os fatos clínicos com os quais Freud lida, mas antes, diz respeito às próprias questões de Freud:

Essa tentativa de formulação hipotética se apresenta com um caráter único no que nos resta escrito de Freud - e não se deve esquecer que ele se cansou dela e não quis publicá-la. Certamente ele a colocou preto no branco para responder às exigências dele com ele mesmo, diante dele mesmo. Mas é preciso dizer que ela não faz referência alguma, pelo menos aparentemente, aos fatos clínicos, que constituem, para Freud, todo o peso das exigências com as quais lida. Aqui, ele está conversando consigo mesmo, ou com Fliess, o que, no caso, é quase a mesma coisa. Ele faz para si mesmo uma representação provável, coerente, uma hipótese de trabalho para responder a algo cuja dimensão se encontra, aqui, mascarada, eludida (Lacan, 1959-60/1988, p. 40).

Sabemos que, à época da elaboração do Projeto, Freud se deparava com o problema de estabelecer uma etiologia sexual para as neuroses. Renato Mezan (2003) defende a tese de que o Projeto serviu para fundamentar quantitativamente a teoria da sedução traumática. O problema do conteúdo sexual das ideias que são penosas ao sujeito já era uma preocupação desde seu trabalho em parceria com Breuer. Nos Estudos Sobre a Histeria (Breuer \& Freud, 1893/1996) as histéricas lhes mostraram que seus sofrimentos sintomáticos ocorriam devido a um conflito psíquico entre as ideias que se encontram em uma corrente de associação normal da consciência, e aquelas outras que são impedidas de entrar em associação com as primeiras, e às quais eram negadas a ab-reação de sua quota afetiva. No artigo As Neuropsicoses de Defesa (1894/1996), Freud afirmou que a defesa se arma contra o investimento em uma ideia intensamente penosa ao sujeito. Vemos, a partir de tais afirmações, que o problema quantitativo serviu à sustentação de sua hipótese neste momento. Uma defesa realizada pelo eu coloca um problema de quantidade, ou de uma intensidade dessas quotas afetivas: se o eu se defende de uma ideia sexual incompatível, esta última deve ter uma intensidade elevada para que este mecanismo alcance seu sucesso (Freud, 1894/1996, p. 73). Qual seria esta intensidade? E ainda, por que estas ideias adquirem esta característica? O que há em relação ao sexual que o torna incompatível? Estas são as perguntas que serviram de guia para a redação do Projeto. 
O que vemos é Freud abandonar a ideia de aparelho psíquico em termos neuronais postulada no Projeto em função da hipótese do inconsciente. Nosso ponto de interesse é atentar a este abandono realizado por Freud de sua principal teses até aquele momento: a de que a neurose é causada por desarranjos energéticos no interior do sistema nervoso. Por outro lado, vemos também os métodos hipnótico, catártico e de "pressão na testa" serem abandonados em detrimento da técnica da associação-livre.

A premissa de que há pensamentos inconscientes fornece as condições para que a psicanálise, a partir de então, estabeleça a lógica para a formação de um sintoma não mais apelando a uma possível objetivação da fisiologia cerebral: não se trata de afirmar uma lógica do funcionamento psíquico em função de uma energia neuronal. Antes, é em torno do que Freud chamou dos mecanismos de condensação e deslocamento como modo de relações entre representações ou, segundo a terminologia lacaniana, significantes -, é que podemos situar a questão da formação de um sintoma. Com efeito, é em função da lógica que comanda a cadeia significante que Freud defende a tese de que os sonhos são realizações de desejos inconscientes.

Um modo novo de se colocar um problema nos indica um impasse que foi superado. Superar um impasse é estabelecer novas coordenadas para se tratar de um problema. Porém, essa superação longe de nos indicar um continuísmo, nos conduz necessariamente à ideia de corte epistemológico. Por isso, acreditamos que a Interpretação dos Sonhos rompe com o ideal cientificista do Projeto. Não há uma evolução gradual dos conceitos que culminaram nas teses centrais da psicanálise em 1900. Acreditamos, ao contrário, que a ideia de ruptura não pode sugerir uma evolução. Os termos utilizados por Freud nos dois textos podem até ser os mesmos - por exemplo, no Projeto já temos a afirmação de que o pensamento é um processo inconsciente, mas não devemos perder de vista que neste o pensamento é definido como um grupo específico de neurônios $(\psi)$ responsáveis pela memória -, mas os conceitos não. Jean-Claude Milner (1996) evoca a teoria lacaniana dos discursos para afirmar que se existe corte entre dois discursos, isto equivale a dizer que entre um e outro não encontramos sinonímia nas proposições. Na obra freudiana, as proposições do Projeto não são sinônimas das proposições da Interpretação dos Sonhos. Para concluir este raciocínio, citemos Milner:
Admitindo-se que a teoria dos discursos é uma literalização dos lugares e dos termos, o corte é, antes de tudo, o apontamento de um impossível literal. Impossível que um sistema de letras seja um outro; impossível para um sistema de letras passar sem transtornos a um outro sistema de letras. Em outras palavras, não existe transformação interna a um sistema; toda transformação é passagem de um sistema a outro (Milner, 1996, p. 49)

Portanto, a proposição "só há pensamentos inconscientes" feita em 1900 levou o aparelho psíquico a uma dinâmica considerada impossível antes de Freud. Os mecanismos de deslocamento e condensação assumiram o papel de operadores de um modo de funcionamento psíquico. Assim, a ruptura que situamos entre estes dois textos diz respeito ao conceito de inconsciente, o qual adquire sentido estritamente psicanalítico a partir de um trabalho de deformação. Sobre a importância deste trabalho, Bachelard afirmou na Filosofia do Não (1978) que "só existe um meio de fazer avançar a ciência; é o de atacar a ciência já constituída, ou seja, mudar sua constituição" (Bachelard, 1978, p. 19). O conceito de inconsciente aparece com a publicação da Interpretação dos Sonhos sistematizado a partir de um trabalho de deformação, característica imprescindível a um procedimento compatível com o espírito científico. Esta é a diferença que pretendemos marcar. No Projeto a marca do cientificismo é um impasse; e um impasse é a condição de um ato. O corte como efeito de um ato deve levar em conta um impasse que foi superado. Em outras palavras, não podemos nos limitar a teses simplistas de que o Projeto é uma falácia científica. Só inserindo o Projeto na série de erros fecundos é que podemos colocar a questão de uma ruptura fundadora da psicanálise.

\section{CONCLUSÃO}

Jacques Lacan afirmou em seu texto Do Sujeito Enfim em Questão (1966/1998) que "o fato de a psicanálise ter nascido da ciência é patente. Que pudesse ter surgido de outro campo é inconcebível" (Lacan, 1966/1998, p. 232). Esta afirmação de Lacan nos aponta que mesmo não sendo uma ciência propriamente dita, a psicanálise está intimamente ligada a esta. Esta ligação diz respeito, segundo Lacan (1965/ 1998), ao fato da psicanálise operar sobre o sujeito da ciência. Segundo Lacan, existe uma relação entre a psicanálise e a ciência que possibilita à psicanálise operar sobre o sujeito da ciência. "Não há ciência do homem porque o homem da ciência não existe, mas apenas seu sujeito" (Lacan, 1965/1998, p. 873). A 
afirmação de que a psicanálise opera sobre um sujeito, e que este sujeito é o sujeito da ciência, só é possível de ser formulada levando em consideração as consequências que o advento da atividade científica moderna implicam. Consequências que, para serem pensadas, devem levar em conta uma epistemologia específica, ou seja, a histórica.

$\mathrm{O}$ advento da atividade científica não implica outra coisa senão em considerarmos o sujeito como um efeito do discurso científico. É em relação a essa disjunção entre saber e verdade que Lacan (1965/ 1998) afirmou que a ciência foraclui a verdade e que seria tarefa da psicanálise se ocupar com o problema da verdade. Segundo Bachelard, no campo científico de problemas não podemos estar às voltas com o problema da verdade. Isso se deve porque se consideramos a atividade científica como sendo da ordem de produção de novos problemas e questionamentos, não faz sentido estabelecermos uma verdade universal para seus princípios e para a lógica de seu discurso. Ora, a atividade científica - sendo aquela que se constitui sob os parâmetros de objetivação, parcialidade e infinitude se coloca que tipos de problemas? Seriam problemas relativos a uma verdade - que em psicanálise entendemos sempre como o sujeito se colocando insatisfeito em relação ao desejo? Essa pergunta, a nosso ver, é fundamental para a psicanálise, pois a ciência, ao tratar de uma objetividade estabelecendo leis e teoremas, afasta o problema de uma verdade para o seu discurso. O problema da verdade no mundo moderno tem um nome, a saber, o sujeito.

Portanto, retornando a Freud, e seguindo esta linha de raciocínio, vemos que é precisamente sob o modelo de um ideal científico que Jean-Claude Milner coloca o problema da relação de Freud com a ciência: se existe uma insistência de Freud em tomar uma experiência clínica, tal como a psicanálise a entende, por uma experiência científica, esta insistência "reside naquilo que concordamos em chamar de cientificismo de Freud, e que nele é apenas um assentimento conferido ao ideal da ciência" (Milner, 1996, p. 30). Em outras palavras, o problema poderia ser assim articulado: o que deve ser a psicanálise para constituir uma ciência conforme o modelo? A preocupação de Milner ao fazer esta afirmação é defender que a psicanálise, ao contrário de se subordinar à ciência, mantém com esta uma relação de compatibilidade lógica.

O ideal de ciência freudiano é, então, um problema, como nos demonstra Milner. Isso porque um princípio cientificista nos aponta um grave impasse. Este princípio não leva em conta uma ruptura entre os campos de problema, uma vez que tudo aquilo que não é científico é desprovido de validade, organização e sentido. Ora, se entre os campos de problemas não há continuísmo, em primeiro lugar devemos questionar se o sentido do problema é científico ou não. Este impasse nos conduz a pensar este princípio como contrário ao pensamento científico. Se a ciência se constitui a partir de uma rede precisa de relações, que se abre ao infinito, sendo a parcialidade uma característica do fenômeno produzido, não é possível traçar um ideal para esta atividade. Sem dúvida, o ideal da ciência traz como efeito uma ciência finita. A afirmação de um ideal científico é verdadeiramente contrário ao caráter inventivo e infinito da ciência; não faz sentido o estabelecimento de um critério que delimitaria este ideal anteriormente ao sentido de um problema.

Com efeito, a compatibilidade lógica entre a psicanálise e a ciência se dá justamente pela separação dos campos de problemas. E, uma vez estabelecida uma não subordinação de um campo de problemas ao outro é que a compatibilidade lógica entre o pensamento psicanalítico e o pensamento científico deve ser traçado a partir de um mesmo princípio para tratar e encaminhar os problemas. A epistemologia da deformação demonstra que $o$ ato de conhecer dá-se contra conhecimentos mal estabelecidos e, a perspectiva de erros retificados é o que precisamente caracteriza o espírito científico. Dessa forma, acreditamos que o pensamento freudiano é solidário à lógica de um mundo moderno, pois, como nos aponta Bachelard:

O cientista não vê que a ignorância é um tecido de erros positivos, tenazes, solidários. Não vê que as trevas espirituais têm uma estrutura e que, nestas condições, toda experiência objetiva correta deve implicar sempre a correção de um erro subjetivo. Mas não é fácil destruir os erros um a um. Eles são coordenados. O espírito científico só se pode construir destruindo o espírito não-científico (Bachelard, 1978, p. 6).

Ao assumir os riscos de falsas construções teóricas e experimentando erros na tentativa de estabelecer a "direção do tratamento", mas se atendo ao sentido de um problema, Freud estabeleceu, a partir do conceito de inconsciente um modo novo de se conceber o psiquismo e, consequentemente, uma clínica, fundando a psicanálise.

Idas e vindas, mudanças de posições que produzem novos problemas: essas são as características da formação de um conhecimento compatível com a lógica científica. E esta lógica, segundo afirmou Bachelard, foge da certeza e da unidade, encontrando na homo- 
geneidade e na identidade do espírito mais obstáculo do que estímulo. Precisar, retificar ou diversificar são tipos de pensamento que podemos apontar como próprios ao espírito científico. Não seria então, por consequência, o pensamento freudiano guiado por um real e não por um ideal científico?

\section{REFERÊNCIAS}

Bachelard, G. (1977). Epistemologia: Trechos escolhidos por Dominique Lecourt. (N. C. Caixeiro, Trad.). Rio de Janeiro: Zahar.

Bachelard, G. (1978). A filosofia do não (J. J. M. Ramos, Trad.). Em J. A. M. Pessanha (Org.), Bachelard (Coleção Os Pensadores) (pp. 03-87). São Paulo: Abril Cultural.

Bachelard, G. (1996). A formação do espírito científico (E. S. Abreu, Trad.). Rio de Janeiro: Contraponto.

Bachelard, G. (1999). A psicanálise do fogo (P. Neves, Trad.). São Paulo: Martins Fontes.

Blanché, R. (1983). A ciência actual e o racionalismo. Porto: Rés.

Breuer, J., \& Freud, S. (1996) Estudos sobre a histeria (J. O. A. Abreu, Trad.). Em J. Salomão (Org.), Edição standard brasileira das obras completas de Sigmund Freud (Vol. 2, pp. 13364). Rio de Janeiro: Imago. (Original publicado em 1893)

Cottet, S. (1989). Freud e o desejo do psicanalista (A. Roitman, Trad.). Rio de Janeiro: Zahar.

Freud, S. (1996). As neuropsicoses de defesa (J. O. A. Abreu, Trad.). Em J. Salomão (Org.), Edição standard brasileira das obras completas de Sigmund Freud (Vol. 3, pp. 55-82). Rio de Janeiro: Imago. (Original publicado em 1894)

Freud, S. (1996). Projeto para uma psicologia científica (J. Salomão, Trad.). Em J. Salomão (Org.), Edição standard brasileira das obras completas de Sigmund Freud (Vol. 1, pp. 381-517). Rio de Janeiro: Imago. (Original publicado em 1895)

Freud, S. (1996). A interpretação dos sonhos (W. Oliveira, Trad.). Em J. Salomão (Org.), Edição standard brasileira das obras completas de Sigmund Freud (Vols. 4 e 5, pp. 39-700). Rio de Janeiro: Imago. (Original publicado em 1900)

Freud, S. (1996). Esboço de psicanálise (E. A. M. Souza, Trad.). Em J. Salomão (Org.), Edição standard brasileira das obras completas de Sigmund Freud (Vol. 23, pp. 165-237). Rio de Janeiro: Imago. (Original publicado em 1938)
Garcia-Roza, L. A. (1991). Introdução a metapsicologia freudiana: Vol. 1. Rio de Janeiro: Zahar.

Koyré, A. (1991) Estudos de história do pensamento científico (M. Ramalho, Trad.). Rio de Janeiro: Forense Universitária.

Lacan, J. (1975). Conferência em Genebra sobre o sintoma. Opção Lacaniana, 23, 6-16.

Lacan, J. (1985). O seminário, livro II: O eu na teoria de Freud e na técnica da psicanálise (M. C. L Penot \& A. Quinet, Trads.). Rio de Janeiro: Zahar. (Original publicado em 1954-55)

Lacan, J. (1986). O seminário, livro I: Os escritos técnicos de Freud (B. Milan, Trad.). Rio de Janeiro: Zahar. (Original publicado em 1953-54)

Lacan, J. (1988). O seminário, livro VII: A ética da psicanálise (A. Quinet, Trad.). Rio de Janeiro: Zahar. (Original publicado em 1959-60)

Lacan, J. (1998). A ciência e a verdade (V. Ribeiro, Trad.). Em J. Lacan (Org.), Escritos (pp. 869-892). Rio de Janeiro: Zahar. (Original publicado em 1965)

Lacan, J. (1998). Do sujeito enfim em questão (V. Ribeiro, Trad.). Em J. Lacan (Org.), Escritos (pp. 229-237). Rio de Janeiro: Zahar. (Original publicado em 1966)

Lacan, J. (1998). De nossos antecedentes (V. Ribeiro, Trad.). Em J. Lacan (Org.), Escritos (pp. 69-76). Rio de Janeiro: Zahar. (Original publicado em 1966)

Lacan, J. (1998). O seminário, livro II: Os quatro conceitos fundamentais da psicanálise (M. D. Magno, Trad.). Rio de Janeiro: Zahar. (Original publicado em 1964)

Lecourt, D. (1969). L'épistémologie historique de Gaston Bachelard. Paris: J. Vrin.

Mezan. R. (2003). Freud: A trama dos conceitos. São Paulo: Perspectiva.

Milner, J. C. (1996). A obra clara (P. Abreu, Trad.). Rio de Janeiro: Zahar.

Ullmo, J. (1967). O pensamento científico moderno. Coimbra: Coimbra Editora.

\section{Sobre o autor:}

Tiago Iwasawa Neves: Professor Assistente da Faculdade Pitágoras (Campus Ipatinga). Mestre em Psicologia pela Universidade Federal de Minas Gerais (UFMG). Colaborador do Núcleo de Pesquisa e Extensão em Psicanálise (NUPEP) da Universidade Federal de São João Del-Rei (UFSJ). Membro do Centro de Estudos e Pesquisa em Psicanálise (Cepp - Vale do Aço).

Endereço para correspondência: Praça Dom Helvécio, 74 - 36310-160 São João del Rei - MG.

Endereço eletrônico: tiagoiwasawa@hotmail.com. 